REVISTA DE LITERATURA E CULTURA RUSSA

\title{
O impacto da biologia tcheca e russa no pensamento linguístico do Círculo Linguístico de Praga segundo princípios biológicos
}

The impact of Czech and Russian biology on the linguistic thought of the Prague Linguistic Circle according to biologic principles

Autor: Patrick Seriót

Universidade de Lausanne, Lausanne, Suíça Romanda Edição: RUS Vol. 12. № 19

Publicação: Agosto de 2021 


\section{O impacto da biologia tcheca e russa no pensamento linguístico do Círculo Linguístico de Praga segundo princípios biológicos}

Patrick Seriót

Resumo: Neste artigo, proponho explorar um aspecto pouco conhecido da biblioteca ideal, ou mundo intelectual, de Jakobson e Trubetskói: o princípio biológico na sua relação com aquilo que atualmente se chama "ecologia global ou holística". De fato, uma parte significativa do foco de interesse dos assim chamados "russospraguenses" deve ser considerada no quadro das controvérsias desse período diante do predomínio do "evolucionismo" na biologia, uma ciência que, por um longo período, antes de a linguística tomar para si esse papel - já após a Segunda Guerra Mundial -, desempenhou a função de modelo para as ciências humanas.

\begin{abstract}
I propose in this paper to explore one poorly known aspect of Jakobson's and Trubetzkoy's ideal library, or intellectual world: the biological background, in its relationship with what would be called nowadays «global, or holistic ecology». As a matter of fact, an important part of the scope of interest of the so-called Prague-Russians is to be put within the framework of controversies of this period in the domain of evolutionism in biology, a science which for a long time played the role of model-supplier for human sciences before linguistics itself took up this role after World War II.
\end{abstract}

Palavras-chave: Círculo Linguístico de Praga; Roman Jakobson; Nikolai Trubetskói; Biologia; Linguística

Keywords: Prague Linguistic Circle; Roman Jakobson; Nikolai Trubetzkoy; Biology; Linguistics 
* Professor de Linguística Eslava na Universidade de Lausanne. Doutor pela Universidade de Grenoble e Mestre em russo pela Universidade de Paris IV. Concluiu sua formação em eslavística na Universidade de Aix-en-Provence. Agradecemos aos professores Patrick Sériot e Tomáš Hoskovec, atualmente administrador dos Travaux du Cercle linguistique de Prague, a permissão para traduzirmos e publicarmos este ensaio neste número da RUS. https:// orcid.org/0000-0002-4805-883X; patrickseriot@yopmail.com

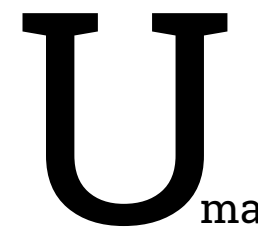

ma leitura superficial da obra multifacetada de Jakobson poderia sugerir que suas inúmeras críticas contra o naturalismo de Schleicher o vinculam à tendência sociológica da linguística, muito difundida na época de Meillet.

No entanto, a tese que desenvolvo aqui é que os dois principais representantes russos do Círculo Linguístico de Praga, longe de seguirem o modelo sociológico que Saussure e Meillet haviam tomado emprestado de Durkheim, basearam-se em uma metáfora biológica, assim como Schl eicher, embora se tratasse de uma metáfora explicitamente antidarwiniana. A questão aqui será descobrir se essa linha antidarwinista, de modo geral, era dominante nesse período na ciência russa e tchecoslovaca ou em todos esses fatores em conjunto. A segunda questão será descobrir se se tratava realmente de uma metáfora e não de uma forma real de se pensar. A última tese que desenvolverei é a que deve ser evitado um mal-entendido quando se fala de estrutura no contexto do Círculo Linguístico de Praga, já que naquela época uma estrutura era, frequentemente, confundida com a ideia de "totalidade" (em russo: tsiélostnost; em tcheco: celek; em alemão: ganzheit).

\section{Teleologia ou causalidade?}

Já foi dito por Jindřich Toman que o antidarwinismo é uma emanação característica da cultura russa. Mas é preciso ser extremamente cuidadoso com o determinismo cultural das atitudes científicas. 
O livro de Darwin A origem das espécies, publicado em 1859, foi traduzido na Rússia apenas em 1864. A teoria darwinista foi assimilada com entusiasmado, como uma visão global do mundo, pela intelligentsia russa "radical", que encontrou nesse pensamento um argumento para o seu anti-idealismo e antirromantismo. Na realidade, Darwin rejeitou qualquer tipo de visão teleológica em favor de uma explicação da evolução em termos de causalidade (a luta pela sobrevivência, a seleção natural e a preservação daquele que estivesse mais apto). As teorias darwinistas foram desenvolvidas na Rússia por acadêmicos como Kliment Timiriazev.

Assim como em outros países europeus, uma reação antidarwinista logo teve início, não apenas nos círculos teleológicos, mas também filosóficos e científicos. Entre seus opositores, o mais importante foi, provavelmente, 0 naturalista de origem báltica, Karl von Baer (1792-1876), que defendia uma noção de desenvolvimento universal pensada segundo o espírito da Naturphilosophie, de Schelling. Ele concebia a evolução como uma expansão gradual da dominação do espírito sobre a matéria, deu continuidade à teleologia aristotélica em lugar da causalidade newtoniana e advogava em favor de uma explicação antimecanicista da evolução. Uma idiossincrasia da conjuntura russa, no entanto, parece ter sido uma espécie de simbiose entre as ciências naturais e o conservadorismo eslavófilo. Assim N. Ia. Danilevski (18221885) ficou conhecido como um filósofo da história com opiniões pan-eslavistas contundentes. No entanto, também era um naturalista e um dos discípulos de von Baer. Em seu livro Darwinismo (1885), ele refuta a causalidade como um fator externo e afirma que a teleologia é a única via de explicação para o fator da evolução. Contudo, é importante notar que sua argumentação é baseada no fato de que o darwinismo é um produto do "materialismo ocidental."

Enquanto Jakobson se refere ocasionalmente a Danilevski (por exemplo, em "O mito francês na Rússia”, 1931), 
é nas citações de von Baer - mais utilizado pelo linguista russo - que ele baseia, sempre que necessário, seus ataques contra um paradigma que ainda era tido como 0 mais moderno nos anos 20 e 30: o princípio de explicação estritamente causal na mudança na linguagem, segundo os neogramáticos. Mas a principal referência no mundo da biologia para Jakobson, em seu período praguense, foi o biólogo russo L. S. Berg (1876-1950). Berg apresenta uma concepção explicitamente antidarwiniana de evolução em 1922, em seu livro Nomogênese (evolução de acordo com as leis) - ao atribuir um importante lugar à noção de conformidade, cujo fim era o de se alcançar um objetivo (tselesoobraznost, em alemão zielstrebigkeit), como uma propriedade de tudo aquilo que é vivo. De acordo com ele, o curso da evolução é predeterminado pela difusão de rudimentos preexistentes. Jakobson se refere frequentemente a Berg quando se esforça para lutar contra o princípio neogramático de causalidade estrita e apresenta seu próprio antidarwinismo. Em 1927, por exemplo, em suas Observações sobre a evolução fonológica do russo em comparação com outras línguas eslavas, ele contrapõe explicitamente a concepção darwinista de evolução em relação à concepção de Berg de evolução, isto é, motivada pela convergência de espécies não relacionadas no mesmo território.

Nesse texto, é possível encontrar as principais teses de Jakobson acerca da evolução das linguagens, o que lhe permitiu refutar os pontos de vista saussurianos, que ele relaciona aos neogramáticos em uma perspectiva epistemológica. Ele afirma que a ciência moderna (e especialmente a ciência russa) pode ser definida pela substituição da pergunta "por quê?" (warum?) pela pergunta "com que finalidade?" (wozu?), sendo que, em 1928, ele propõe "uma substituição da abordagem teleológica por uma perspectiva mecanicista."

1 JAKOBSON, 1971, p. 2 
É notável que Jakobson não faça uma analogia com o objeto - assim como faz Schleicher, para quem as línguas são, de fato, organismos vivos -, mas, sim, com o método, isto é, segundo ele, é possível estudar a evolução das línguas da mesma maneira que se estuda a evolução dos seres vivos.

\section{Nomogêneses ou acaso?}

Uma particularidade da crítica russa ao darwinismo é a permanência do conflito entre a evolução ocorrida por mero acaso e a evolução regida por leis. Não restam dúvidas que há uma leitura tendenciosamente darwinista: Darwin afirma frequentemente que a evolução está sujeita a leis e regularidades. Mas essas leis baseadas na causalidade não puderam satisfazer os seus opositores russos: apenas um modelo determinista e previsível pode ser considerado uma lei.

Danilevski censura Darwin por negligenciar o aspecto teleológico e predeterminado da evolução, que ele designa ortogênese.

Berg menciona Danilevski e acredita ser possível substituir o acaso darwiniano pela ideia de nomogênese ou uma evolução baseada em leis. Trata-se de uma teoria da evolução "autogenética", que postula que a evolução é um desenvolvimento de rudimentos ou potencialidades preexistentes (como no modelo embriológico), ao invés de uma série de respostas adaptativas às espécies do seu entorno, com a formação aleatória de novas características, como é para Darwin.

É necessário adicionar a esse determinismo interno um determinismo externo, devido à "paisagem geográfica" ou "landšaft", que atua como uma ação delimitadora que obriga todas as espécies a "variar em uma mesma direção."2 Essa é outra fonte de inspiração para a visão 
de Jakobson e Trubetskói, vinda do geógrafo eurasianista que vivia em Praga, P. N. Savítski. Acredito que a influência de Savítski, sobre Trubetskói e Jakobson, não deve ser subestimada. Pelo contrário, é digna de atenção. Para Savítski - e Trubetskói, pelo menos até o início dos anos 30 -, uma estrutura não é um conjunto de oposições negativas, como para Saussure, mas, sim, um elo entre coisas já existentes, porém geneticamente não conectadas. A famosa fórmula "un système où tout se tient"3 pode estar por trás das duas definições do conceito de "estrutura."

Estamos aqui no centro de um problema clássico da epistemologia, que diz respeito ao modo de ser dos objetos de conhecimento. Para Trubetskói, havia uma ligação entre as línguas turcas, a mentalidade turca, as canções turcas e os ornamentos turcos. O mundo turco ou turaniano é uma totalidade positiva. E o objetivo do trabalho científico é, precisamente, a verificação empírica da existência ontológica dessa totalidade. Acredito que mesmo o problema filosófico da existência da Rússia, para Trubetskói, deve ser levado em consideração para se compreender a história da noção de estrutura. Mas gostaria de enfatizar que esse estruturalismo era uma teoria de correspondências, ou de coincidências.

Ao examinar com atenção as críticas de Jakobson à visão de Saussure sobre a evolução linguística, seja na Proposição 22 para o Congresso em Haia (1928) ou nas Teses de 1929, é possível trazer à luz a oposição estrita entre os dois paradigmas. Jakobson insiste no fato de que a concepção de Saussure sobre a evolução linguística é baseada em "acasos aleatórios sem quaisquer objetivos"4 (Ele aponta como fonte dessas ideias, no trabalho de Saussure, para Schleicher e os neogramáticos).

\footnotetext{
3 Francês para "um sistema em que tudo se encaixa". (N.T.)

4 JAKOBSON, 1971, "Remarques sur l'évolution phonologique du russe comparée à celle des autres langues slaves", SW1, p. 17; p. 110.
} 
Portanto, é possível, ao inverter os argumentos um a um, reconstruir o modelo nomogenético de evolução defendido por Jakobson. Mas essa insistência no caráter aleatório da evolução atribuído ao darwinismo é curiosa e deve ser examinada minuciosamente.

Jakobson repete diversas vezes, entre os anos 20 e 30, que a nomogênese, segundo a qual as línguas podem evoluir apenas em uma única direção e de acordo com as leis do sistema, é algo totalmente novo se comparado às teorias anteriores. Essas teorias precedentes são o naturalismo de Scheicher e o positivismo dos neogramáticos. Mas o que é mais surpreendente é que tanto Schleicher quanto os neogramáticos insistem constantemente no fato de que trabalham com leis (seria possível pensar no princípio ausnahmlosigkeit dos neogramáticos ${ }^{5}$ ). Mas essa lacuna não seria apenas temporal. Para Jakobson, os paradigmas científicos também têm uma dimensão espacial, ou seja, cultural: há a assim chamada "ideologia europeia", que ele opõe à chamada "ideologia contemporânea," sobre a qual a "ciência russa" desempenha um papel peculiar. A primeira reconhece apenas o acaso cego na evolução; a segunda apresenta uma evolução orientada para um objetivo. Essa teoria das duas ciências está explicitamente estabelecida em um artigo fascinante que Jakobson publicou no Slawische Rundschau, em 1929: "Über die heutige Voraussetzungen der russische Slavistik".

Deve-se notar, por fim, que essa polêmica sobre o acaso ou a necessidade na evolução, que surgiu no final do século 19 e no início do século 20, não assumiu formas tão apaixonadas como na URSS, onde Lyssenko declarou que "o acaso é estranho à ciência" e rejeitou a noção de variação ou mutação aleatória. O lyssenkismo na biologia soviética é contemporâneo ao desenvolvimento de concepções antidarwinistas entre certos membros do Círculo Linguístico de Praga.

5 "Admitir desvios fortuitos, impossíveis de coordenar, é afirmar, na realidade, que o objeto da nossa ciência, a linguagem, é inacessível à ciência" (LESKIEN apud HARRIS; TAYLOR, 1991, p. 171). 


\section{Convergências ou divergências?}

\section{a) Peixes e baleias}

Durante a reunião de fundação do Círculo Linguístico de Praga (6 de outubro de 1926) no gabinete de Mathesius na Charles University, em Praga, Jakobson, Mathesius e outros quatro colegas se reuniram para discutir o artigo de Henrik Becker, de Leipzig: "Der europäische Sprachgeist," que fora finalizado naquele mesmo dia. A discussão era que o tcheco e o húngaro, duas línguas sem qualquer relação genética, eram, de fato, profundamente marcadas por seu contato permanente através do território: eles estavam ligados "pela cultura" e não "pela natureza." Essa problemática estava em total oposição com a teoria genética de "árvore genealógica", frequentemente aceita no século XIX. Mas essa nova abordagem lança uma nova luz se a associarmos à controvérsia biológica contemporânea.

Mais uma vez, ao rejeitar a ideia de evolução arbitrária dos seres vivos, L. Berg chegou à teoria da evolução por convergência. Para ele, a probabilidade do aparecimento arbitrário de uma mesma característica em duas espécies diferentes ao mesmo tempo é próxima de zero (BERG, 1922, p. 105). Ele, por outro lado, descobriu que organismos sem uma ligação genética comum podem adquirir características iguais, dando um exemplo bastante simples: as baleias são mamíferas, mas desenvolveram características semelhantes às dos peixes, elas se "tornaram" uma espécie de peixe por viverem no mesmo ambiente que eles. A mesma ideia pode ser vista em um livro escrito por Emanuel Rádl (The history of biological theories, escrito em alemão em 1909, traduzido para o inglês em 1930, pp. 109-115), um filósofo tcheco, professor de filosofia natural na Universidade de Praga.

6 MATEJKA, 1978, p. ix. 


\section{b) Cadeias e tijolos}

A noção de afinidades adquiridas havia sido incorporada ao espírito da época desde que, depois da guerra de 1870 , os franceses, os alemães e os italianos começaram a estudar uma linguística areal. ${ }^{7}$ Hugo Schuchardt propõe a ideia de "afinidade linguística" (sprachverwandschaft), e esta terminologia é retomada diretamente por Jakobson, com o termo iazykovoe srodstvo. ${ }^{8}$

No período entreguerras foram feitas, na Europa, tentativas de estudar as influências mútuas de dialetos vizinhos, para determinar por que, em um mesmo contexto geográfico, línguas de origens totalmente diferentes se parecem. O linguista holandês C. C. Uhlenbeck (18661951) via uma família linguística como o resultado de uma longa assimilação de línguas em contato. Ele aplica a ideia de família linguística ao conceito antropológico de aculturação, que consiste na adaptação de traços culturais tomados de empréstimo de uma cultura para outra. Esse tipo de pesquisa foi retomado pela escola dos neolinguístas, na Itália, no final dos anos 30.

No início de 1923, Trubetskói cunhou o termo "união de línguas" (iazykovoi soiuz) em um ensaio teológico sobre a pluralidade de línguas, "A Torre de Babel e a confusão das línguas."9 Em 1928, em Haia, ele propôs o termo de

\footnotetext{
7 A expressão "linguística areal" ou "linguística espacial", também chamada de neogramática, segundo Patrick Sériot, em Estrutura e totalidade, "formou-se na Itália entre 1920 e 1940. Seus representantes mais eminentes são Matteo Bartoli (1873-1946), Giulio Bertoni (1878-1942) e Vittorre Pisani (1899-1975). Alunos de G. Ascoli, os neolinguistas elaboraram uma teoria geolinguística próxima daquela de J. Gilliéron, mas com conotações idealistas devidas à influência de B. Croce. Em sua prática, eles mostraram que é impossível encontrar duas isoglossas em perfeita coincidência, e que não há, portanto, nenhuma descontinuidade estrita entre os dialetos. Uma língua é, para eles, um "sistema de isoglossas". Consideravam, assim, a geografia linguística como o estudo da difusão de fenômenos linguísticos, a partir de um certo e por meio de irradiação para uma periferia, não importando o lugar que pudesse ser o centro. Os neolinguistas se interessaram, nos anos 1930-1940, pelo fenômeno das uniões de línguas (lega linguistica), que explicavam, diferentemente de Jakobson, pela teoria do substrato. (SÉRIOT, 2016, P. 121) (N. do E.)

8 Deve-se notar que Jakobson também se refere a Goethe como um biólogo, e traduz Wahlverwandschaft ("afinidade seletiva") por "convergência de desenvolvimento" (JAKOBSON, "Sur la théorie des affinités phonologiques entre les langues", SW-I, p. 236).
}

9 Evraziski Vremennik III; TRUBETZKOI, 1991, pp.147-160. 
Sprachbund. Nosso colega J. Toman estudou exaustivamente esse tema, tratarei aqui apenas do contexto biológico, lembrando que, em 1936, quando Jakobson falava sobre a necessidade das afinidades fonológicas entre as línguas, ele estava muito próximo da noção ecológica de associação botânica: "a área de politomia geralmente faz fronteira com a zona oclusiva glotal."10

Desde o final do século XIX, a noção de hibridização tem sido uma questão muito recorrente na biologia. Esse era um interesse semelhante ao que na linguística é a noção de sprachmischung, utilizada por Schuchardt, Baudouin de Courtenay e Chtcherba. O linguista soviético N. Marr usou essa mesma ideia, sob o nome de "cruzamento de línguas" (skreščenie). Esse conceito, profundamente enraizado no espírito da época, ganha uma relevância extrema por parte de Trubetskói em uma comunicação junto ao Círculo Linguístico de Praga em 1936: Gedanken über das Indogermanenproblem. Para Trubetskói, línguas que a princípio eram diferentes, que não apresentavam ligação genética, devido ao contato territorial, tornaram-se indo-europeias por convergência, e agora parecem tijolos numa parede.

Para Trubetskói, por outro lado, a evolução das línguas eslavas é completamente distinta: elas surgiram por divergência de um ancestral comum, e agora sua repartição geográfica forma os elos de uma cadeia (ou melhor, uma cota de malha).

Esse texto de 1936, Gedanken über das Indogermanenproblem, deve ser compreendido como uma argumentação contra as teorias nazistas sobre as origens étnicas e genéticas dos "povos indo-arianos ou indo-germânicos". Mas esse estudo também faz sentido no contexto de um debate mais antigo, acerca da evolução das línguas, que, por sua vez, é uma parte da discussão sobre a evolução das espécies vivas.

Acredito que é preciso levar a sério a oposição neolamarckismo vs. darwinismo do início do século XX. O la-

10 JAKOBSON, 1971, "Sur la théorie des affinités phonologiques entre les langues," p. 245. 
marckismo é conhecido por duas teses: a do desenvolvimento mais frequente de alguns órgãos por meio de atividades físicas ou pela ausência dessas, e a da herança dos caracteres adquiridos. Mas outro aspecto do lamarckismo deve ser levado em consideração: sua orientação em direção a um objetivo, sua ideia de uma força interior, algo não muito distante do vitalismo.

Ao ler atentamente os trabalhos de Trubetskói, a sua terminologia peculiar, como "a lógica da evolução", "os sujeitos da evolução", adquire um novo sentido à luz das concepções neovitalistas sobre evolução.

Por isso, acredito que, para Trubetskói e Jakobson, durante o período pré-guerra, a totalidade era, antes de qualquer coisa, não um conjunto de oposições negativas, tal como postulado por Saussure, mas, sim, algo real, com uma existência ontológica real.

A peculiaridade da atmosfera intelectual do neo-lamarckismo do Círculo Linguístico de Praga é que, para Trubetskói, Jakobson e Savítski, não era importante saber se um organismo cultural escolheu seu ambiente físico ou, ao contrário, se o ambiente físico determinou completamente o organismo cultural.

\section{Conclusão}

Mesmo que não se reduza a isso, o estruturalismo dos chamados russo-praguenses esteve profundamente envolvido em uma discussão epistemológica referente às ciências naturais do final do século XIX. Essa discussão foi introduzida na linguística como uma metáfora, mas a metáfora em si não estava longe de ser um modelo de pensamento. Apesar da oposição de Jakobson entre a "ciência europeia", supostamente positivista, e uma ciência russa, supostamente sintética, holística e "vanguardista", temáticas como holismo e teleologia foram amplamente difundidos na biologia daquela época (no 
período entreguerras), tanto na Europa Ocidental e Central quanto na Rússia. A especificidade dos membros do Círculo Linguístico de Praga parece ter permitido se fazer sentir a riqueza desta fonte de inspiração. Nesse sentido, o pensamento biológico na Tchecoslováquia estava no espírito da época, poderia ainda se dizer que o holismo foi, talvez, mais amplamente difundido na filosofia do que em países como a França.

De todo o modo, o holismo foi uma tendência amplamente propagada pelos biólogos tchecos durante os anos 20 e 30. Um de seus maiores expoentes foi o professor Jan Belehrádek, que escreveu os ensaios "Holismus" e "Filosofie celku", ao final dos anos 30.

Seria possível ainda citar outros temas da controvérsia biológica da época que serviram de fonte de inspiração para o estruturalismo praguense: a desaprovação geral do darwinismo na Tchecoslováquia e na Rússia, a oposição entre catastrofismo e unitarismo (enquanto para Darwin Natura non facit saltus, para Berg e Jakobson, mas também Marr, existem, sim, saltos e mudanças repentinas na evolução linguística) ou a oposição esquerdista russa ao darwinismo, que contestava a ideia de luta pela vida em nome do "princípio de cooperação" (tenho em mente especificamente $o$ anarquista Kropotkin e Lyssenko). A minha conclusão é que enxergar uma estrutura como uma totalidade determinada foi um passo atrás necessário que tornou possível um fantástico passo à frete em direção à teoria dos sistemas, como a de Von Bertalanffy - depois da II Guerra Mundial -, e, posteriormente, a teoria da complexidade de Edgar Morin.

Por fim, gostaria que ficasse claro que o conceito de "mudança de paradigma" de Thomas Kuhn dificilmente é aplicado a esses tópicos, isso é, à estrutura e à totalidade. O estruturalismo de Trubetskói e Jakobson funcionava à feição de um movimento pendular, ora para trás, ora para a frente, ele está baseado em uma noção que existia antes mesmo do advento dos neogramáticos: organicismo, 
ao mesmo tempo que a rejeita, afirmando que a linguística é uma ciência social, dela se vale para avançar para a noção moderna de estrutura.

\section{Referências bibliográficas}

BAER, Karl E. von. Reden gehalten in wissenschaftlichen Versammlungen und kleinere Aufsätze vermischten Inhalts, São Petersburgo: Schmitzdorff, 1876.

BELEHRADEK, Jan. "Holismus". Biologické Listy, 22, 1937, pp. 169-179.

BELEHRADEK, Jan. "Filosofie celku”. Věda a Život, ročnik 4, 1937, pp. 385-391.

BERG, Lev S. Nomogenez (Evoljucija na osnove zakonomernostej), Petrogrado: Gosudarstvennoe izdatel'stvo, 1922. (English translation: Nomogenesis, Cambridge Mass., 1966).

BERTALANFFY, L. von. General System Theory: Foundations, Development, Applications. Nova Iorque: G. Braziller Inc., 1968.

DANILEVSKIJ, Nikolaj Jakovlevič. Darvinizm. Kritičeskoe issledovanie, t. 1-2, São Petersburgo: Komarov, 1885.

DARWIN, Charles. The Origin of Species by Means of Natural Selection, or the Preservation of Favoured Races in the Struggle for Life. Londres: John Murray, 1859.

HARRIS, Roy; TAYLOR, Talbot J. Landmarks in Linguistic Thought (the Wester Tradition from Socrates to Saussure). Londres: Routledge, 1991.

JAKOBSON, Roman. "O hláskoslovném zákonu a teologickém hláskosloví". In: Časopis pro moderní filologii, 14, 1928, p. 183184 [The Concept of the sound law and the teleological criterion]. - English translation see in SW-I, pp. 1-2. 
JAKOBSON, Roman. Remarques sur l'évolution phonologique du russe comparée à celle des autres langues slaves (TCLP, 2), 1929a - reprinted in SW-I, pp. 7-116.

JAKOBSON, Roman. "Über die heutigen Voraussetzungen der russischen Slavistk", Slavische Rundschau, 1, 1929b, pp. 629646.

JAKOBSON, Roman."Der russische Frankreich-Mythus", Slavische Rundschau, 3, 1931, pp. 450-454.

JAKOBSON, Roman."Sur la théorie des affinités phonologiques entre les langues", Actes du Quatrième congrès international de lin guistes tenu à Copenhague du 27 août au ler septembre 1936, pp. 45-58, Copenhague: Munksgaad, 1938. - The rev. version from 1949 ("Sur la théorie des affinités phonologiques entre les langues" in N.S. Troubetzkoy: Principes de phonologie, Paris, pp. 351-365) see in SW-I, pp. 234-246.

JAKOBSON, Roman. Selected Writings, vol.1, Haia; Paris: Mouton, 1971.

LESKIEN, August. Die declination im slavisch-litauischen und germanische, Leipzig, 1876.

MATEJKA, Ladislav. "Preface". Sound, Sign and Meaning. Quinquagenary of the Prague Linguistic Circle, Ann Arbor: Michigan Slavic Circle, 1978.

MORIN, Edgar. Introduction à la pensée complexe, Paris: ESF, 1990.

MORIN, Edgar. «Thèses présentées au Premier congrès de philologues slaves», TCLP-1, p. 5-29. - Reprinted in: VACHEK, J. A Prague School Reader in Linguistics. Bloomington: Indiana University Press, pp. 33-58.

TOMAN, Jindřich. "The Ecological Connection: a Note on Geography and the Prague School". Lingua e stile, 16, 1981, pp. 271-282.

TRUBETZKOY, Nikolaj S. "Vavilonskaja bašnja i smešenie jazykov". Evrazjskij vremennik, III, 1923, p. 107-124, Berlin. English translation («The tower of Babel and the confusion of tongues») see in Trubetzkoy 1991, p. 147-160.

TRUBETZKOY, Nikolaj S. "Gedanken über das Indogerma- 
O impacto da biologia tcheca e russa no pensamento linguístico

nenproblem". Acta Linguistica, I, 1939, p. 81-89.

TRUBETZKOY, Nikolaj S. The Legacy of Genghis Khan, ed. by

A. Lieberman, Ann Arbor: Michigan Slavic Circle, 1991.

Traduzido por Raquel Siphone ${ }^{11}$

Recebido em 09/06/2021

Aceito em 16/08/2021

11 Mestranda em Teoria Literária e Literatura Comparada de Letras na Faculdade de Filosofia, Letras e Ciências Humanas da Universidade de São Paulo (FFLCH-USP); https://orcid. org/0000-0003-2259-7517; siphoneraquel@gmail.com 